\title{
Salivary flow rate and radioactivity in saliva, blood and serum of benign and malignant thyroid patients after 131I therapy
}

\author{
A. Rakha1 ${ }^{*}$, K. Rehman², M. Shahid², N. Jahan', M. Babar Imran4 \\ ${ }^{1}$ Department of Biochemistry, Punjab Medical College, Faisalabad, Pakistan. \\ ${ }^{2}$ Department of Biochemistry, University of Agriculture, Faisalabad, Pakistan. \\ ${ }^{3}$ Department of Chemistry, University of Agriculture, Faisalabad, Pakistan. \\ ${ }^{4}$ Pakistan Institute of Nuclear Medicine (PINUM), Faisalabad, Pakistan.
}

\section{- Original article}

*Corresponding authors:
Allah Rakha,PhD.,
E-mail:
$\quad$ drarmalik45@gmail.com
Revised: March 2020
Accepted: May 2020
Int. J. Radiat. Res., January 2021;
19(1): 197-203
DOI: 10.29252/ijrr.19.1.135

\begin{abstract}
Background: Salivary flow rate (SFR), to estimate salivary gland dysfunction and radioactivity in different body fluids, to evaluate its intensity, were determined in thyroid patients after 131-I therapy. Material and Methods: For determination of SFR an innovative sponge test was adopted and the radioactivity in saliva, blood and serum of thyroid patients was determined by Nal (TI) Scintillation Radiation Detector. Results: There was a significant reduction in SFR at 2 weeks after RAIT. At 3 hours after administration of $555-1073 \mathrm{MBq}$ to the benign thyroid patients, the radioactivity in $1 \mathrm{~g}$ of saliva, $2.5 \mathrm{~mL}$ of blood and $0.6 \mathrm{~mL}$ of serum was $17.24,0.74$ and $0.25 \mathrm{MBq}$ respectively. In the same patients, at 2 weeks after RAIT, the radioactivity was decreased and was found to be $0.22,0.13$ and $0.09 \mathrm{MBq}$ in saliva, blood and serum respectively. In malignant thyroid patients treated with 3700-9250 $\mathrm{MBq}$, the radioactivity at 3 hours after RAIT in the studied samples of saliva, blood and serum was 200.72, 9.14 and 3.07 MBq and at 2 weeks after RAIT, radioactivity in samples was decreased up to $0.15,0.05$ and $0.03 \mathrm{MBq}$ respectively. Conclusions: An indigenously designed sponge test was simple, safe and quick method to determine the SFR. The sudden increase of radioactivity was found in all studied samples within 3 hours after RAIT and reduced significantly at 2 weeks after RAIT. The raised radioactivity at 3 hours after RAIT was sufficient to impart its harmful effects even to all interactive persons.
\end{abstract}

Keywords: Radioiodine therapy, Radioactivity in saliva, Radioactivity in blood, Radioactivity in serum.

\section{INTRODUCTION}

Hyperthyroidism is a health menace throughout the world and its prevalence has increased in many countries during the last decade (1). Management of benign hyperthyroidism as well as malignant thyroid diseases with iodine-131 is the standard therapy all over the world (2) but ${ }^{131}$ I is taking its toll in the form of oxidative stress in the body and damage to the non-targeted tissues. Iodine is taken up and concentrated in the thyroid tissue by sodium iodide symporter and this protein channel is also expressed in salivary glands. After the thyroid tissues, the salivary glands are the major glands that concentrate and secrete the radioiodine in saliva (3).

The known adverse effect of 131I therapy is sialadenitis and salivary gland dysfunction leading to xerostomia (4). Radioiodine has a half-life of 8.01 days and emits high energy beta particles and gamma rays (5). Due to the presence of radioactive iodine in the body tissues and fluids, after radioactive iodine therapy (RAIT), patients are isolated for some days at home or at hospital to avoid the 
radiation exposures to others.

Nevertheless, there might be a need to analyze the body fluids of such patients for the management of co-existing morbidities like uncontrolled diabetes mellitus, cardiac and liver diseases etc. Furthermore it is a matter of special care when such patients are included in research work to determine the oxidative effect of ${ }^{131}$ I on different tissues and multiple types of analysis including physical, biochemical, hematological and endocrinological assays are required. Thus the medical health professionals, researchers and laboratory workers may be involved in the manipulation of radioactive blood, serum and saliva samples. The patients of benign hyperthyroid disease are treated with low activity of 131I and the patients suffering from cancerous thyroid disorders got high activity of 131I for ablation of remnant and metastatic thyroidal tissues in the body after thyroidectomy.

There are constantly raised questions that how much radiation is present in these body fluids in patients receiving the RAIT. The aim of this study was to collect the saliva by newly designed sponge test to determine the salivary flow rate (SFR) of thyroid patients after radioiodine therapy and also the amount of radiation in saliva, blood and serum. The laboratory personals are frequently exposed to radioactive body fluids during sample collection and preparation of blood films.

Therefore this study will provide the indigenous data for the health workers and health personals those are in close contact with the patients after RAIT and also have involved in manipulation and interaction with patients. The outcome of the study will guide and provide the data for phlebotomist, laboratory technicians, biochemist, pathologist and physicians who are frequently in contact with the thyroid patients receiving RAIT, in addition to the routine radiation safety guidelines.

\section{MATERIALS AND METHODS}

The present clinical study was prospective and initiated after the approval of ethical review committee for human (ERCH) at Punjab Medical College, Faisalabad (Registration No. 702/2016). The research was conducted at Pakistan Institute of Nuclear Medicine (PINUM) Cancer Hospital, Faisalabad. The inclusion criterion for the benign thyroid group was the patients suffering from diffuse toxic goiter, multinodular toxic goiter and toxic hot nodule, while inclusion criteria for malignant thyroid group was the patients suffering from differentiated thyroid cancers (papillary, follicular, Hurthle cell thyroid cancer and medullary thyroid cancer) at least four weeks after thyroidectomy. The common inclusion criteria was an age limit of 18 to 60 years and interval of 4 weeks of hormonal withdrawl (thyroxin was withdrawn before administration of ${ }^{131} \mathrm{I}$ ). The common exclusion criteria for both these groups were pregnancy, lactation, acute and chronic inflammatory diseases, renal and heart failure and allergy to the ${ }^{131}$ I. Written informed consent was signed by the volunteer patients coming for the treatment of their thyroid disorders. A total of 54 patients of both urban and rural areas of Punjab (Pakistan), suffering from benign thyroid diseases $(n=39) 11$ males and 28 females and patients of malignant thyroid disorders $(n=15) 7$ men and 8 women were enrolled for this study. To the benign thyroid patients' low dose of ${ }^{131} \mathrm{I}$, ranging from 555-1073 MBq was administered while the malignant thyroid patients were treated with high dose of 131I in the range of 3700-9250 MBq. The diagnosis was made and radioiodine therapy was administered by the nuclear physician and the expert staff of the hospital. After 3 hours and at 2 weeks of RAIT, SFR of 10 patients suffering from benign $(n=6)$ and malignant $(n=4)$ thyroid diseases was determined. Furthermore the saliva, blood and serum samples collected from all the 54 patients were examined to quantify the radioactivity in them. The radioactive saliva was collected by the indigenously designed "sponge test" that was the modified form of cotton swab method (6). The sterilized Raband ${ }^{\circledR}$ absorbent starch free cotton gauze pieces of woven fabrics, manufactured by surgical textiles private limited, commonly used in surgical procedures for sponging and dressing were used in sponge test. Two rolled gauze 
pieces of about equal size (4-5 cm long) were packed in polythene zipper and weighed (figure 1A). These gauze pieces were placed by the volunteer in his/her mouth, each on either side in the space between cheeks and teeth, then mouth closed for one minute After prescribed time the sponges were removed, repacked in the same zipper and reweighed (figure 1B). The quantity of saliva absorbed by the sponge was the SFR in grams per minute. The steps of sponge test are given in figure 1.

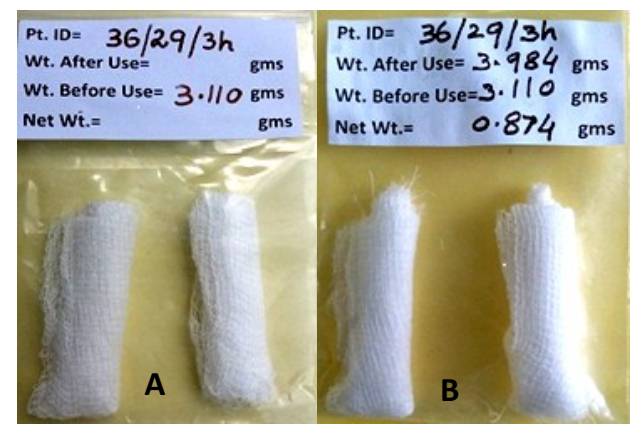

Figure 1. Different steps of sponge test to collect saliva. A, weight of sponges before use; $B$, Net weight of saliva (SFR).

The radiation count was detected by the NaI (TI) Scintillation Radiation Detector of Biodex Medical System, USA (7). The blood samples (5 $\mathrm{mL}$ each) were obtained from the forearm veins by venipuncture, in disposable syringe after observing the antiseptic measures while patients sitting in chairs (8). Out of $5 \mathrm{~mL}$ of blood, $2.5 \mathrm{~mL}$ aliquot was added in EDTA vacutainer for radiation count and for the preparation of peripheral blood film using $15 \mu \mathrm{L}$ of blood. The remaining $2.5 \mathrm{~mL}$ of blood was allowed to clot in the syringe. From the clotted blood the serum was separated after centrifugation at $3000 \mathrm{rpm}$ for 10 minutes. A $600 \mu \mathrm{L}$ of serum was pipetted in the eppendorf tube for determination of radiation count. The blood $(2.5 \mathrm{~mL})$, serum $(600$ $\mu \mathrm{L})$ and glass slides (15 $\mu \mathrm{L}$ blood) were examined under Scintillation Radiation Detector for one minute to determine the count per minute (CPM) in the samples. At the end of procedure these samples were deposited in radioactive waste storage room.

Radiation counts (CPM) of known activities of 131I were determined in the start, in the mid and at the end of experiment. The mean of these Int. J. Radiat. Res., Vol. 19 No. 1, January 2021 values was calculated as a standard factor and 1 CPM represented $0.0000507381 \mathrm{MBq}$. The back ground radiation count was detected as negative control. The amount of radioactivity in these samples was determined as follow.

1. Amount of radioactivity (MBq) per CPM in standard $=\frac{\text { Activity of standard }(\mathrm{MBq})}{\text { count per minute of standard }}=\mathbf{R}$

2. Amount of radioactivity in samples (MBq) $=\mathrm{CPM}$ in sample $\times \mathrm{R}$

Where $\mathrm{R}$ is the amount of radioactivity (MBq) per CPM as calculated in standard activity of ${ }^{131} \mathrm{I}$.

\section{Statistical analysis}

The mean \pm SD of CPM was calculated using the Microsoft office Excel 2010. The megabecquerel $(\mathrm{MBq})$ activity in these samples was calculated by using the equations 1 and 2 . The absorbed radiation dose was calculated by online Rad Pro Calculator (http:// www.radprocalculator.com/Gamma.aspx). The data was presented in tabulated form.

\section{RESULTS}

\section{Salivary flow rate}

The overall mean salivary flow rate (SFR) of whole saliva of thyroid patients at 3 hours after RAIT was $1.157 \mathrm{~g} / \mathrm{min}$ that decreased to 0.648 $\mathrm{g} / \mathrm{min}$ at 2 weeks after RAIT showing $44 \%$ reduction in SFR. The average salivary flow rate (SFR) of benign thyroid patients at 3 hours was $0.963 \mathrm{~g} / \mathrm{min}$ and it was reduced to $0.709 \mathrm{~g} / \mathrm{min}$ within 2 weeks of treatment having 26\% reduction in SFR. The mean SFR of malignant thyroid patient at 3 hours of RAIT was $1.497 \mathrm{~g} /$ min which was significantly reduced to $0.540 \mathrm{~g} /$ min at 2 weeks after RAIT resulting in $63 \%$ reduction in SFR. Internationally accepted standard of cutoff values of minimal SFRs in males and in females are $(0.1 \mathrm{~g} / \mathrm{min})$ and $(0.05$ $\mathrm{g} / \mathrm{min}$ ) respectively ${ }^{(9)}$. The SFR of benign and malignant thyroid patients is given in table 1 . 
Rakha et al. / Radioactivity in body fluids after ${ }^{131}$ / therapy

Table 1. Salivary flow rate determined by sponge test in thyroid patients after RAIT.

\begin{tabular}{|c|c|c|c|c|c|c|c|}
\hline \multirow[b]{2}{*}{ S \# } & \multirow[b]{2}{*}{ Patient wt (kg) } & \multirow[b]{2}{*}{ Gender } & \multirow[b]{2}{*}{ Age (year) } & \multirow[b]{2}{*}{ Disease category } & \multirow[b]{2}{*}{ Activity (MBq) } & \multicolumn{2}{|c|}{ Salivary flow rate (g/min) } \\
\hline & & & & & & At 3 hours after RAIT & At 2 weeks after RAIT \\
\hline 1 & 47 & $\mathrm{~F}$ & 25 & Benign & 740 & 0.788 & 0.557 \\
\hline 2 & 60 & $\mathrm{~F}$ & 45 & Benign & 925 & 1.08 & 0.945 \\
\hline 3 & 64 & $\mathrm{~F}$ & 40 & Benign & 1073 & 0.437 & 0.324 \\
\hline 4 & 63 & $\mathrm{~F}$ & 40 & Benign & 1073 & 1.526 & 0.973 \\
\hline 5 & 41 & $\mathrm{~F}$ & 45 & Benign & 1073 & 0.973 & 0.882 \\
\hline \multirow[t]{2}{*}{6} & 66 & $M$ & 35 & Benign & 1073 & 0.975 & 0.575 \\
\hline & & & & & Mean & 0.963 & 0.709 \\
\hline 7 & 77 & $\mathrm{~F}$ & 34 & Malignant & 7400 & 0.355 & 0.311 \\
\hline 8 & 55 & $\mathrm{~F}$ & 22 & Malignant & 7400 & 0.834 & 0.423 \\
\hline 9 & 66 & $M$ & 27 & Malignant & 7400 & 2.782 & 0.564 \\
\hline \multirow[t]{3}{*}{10} & 84 & $M$ & 49 & Malignant & 7400 & 2.015 & 0.863 \\
\hline & & & & & Mean & 1.497 & 0.540 \\
\hline & & & & \multicolumn{2}{|c|}{ Overall Mean SFR } & 1.157 & 0.648 \\
\hline
\end{tabular}

\section{The radiation counts in saliva}

The CPM in saliva after 3 hours of administration of RAIT was alarmingly high in all the 54 patients. The CPM showed positive correlation with the dose of RAIT. The radiation count was significantly high in saliva of those individuals who were treated with high activity of 131I than CPM in saliva of those treated with low activity radioiodine. At 3 hours after low dose of radioiodine, in $1 \mathrm{~g}$ of saliva of benign thyroid patients, the radioactivity was 339,993 CPM equivalent to $17.24 \mathrm{MBq}$ of ${ }^{131}$ I having dose rate of $8.34 \mathrm{mSv} / \mathrm{hr}$ at $4 \pi$ geometry at a distance of $1 \mathrm{~cm}$ as calculated by standard factor and Rad Pro Calculator. While at 2 weeks after RAIT, in $1 \mathrm{~g}$ of saliva the radioactivity reduced to $4351 \mathrm{CPM}$ which is equal to $0.22 \mathrm{MBq}$ with a dose rate of $0.106 \mathrm{mSv} / \mathrm{hr}$. In malignant thyroid patients at 3 hours after RAIT, in $1 \mathrm{~g}$ of saliva the radioactivity was $3,955,820 \mathrm{CPM}$, equivalent to $200.73 \mathrm{MBq}$ with a dose rate of $96.84 \mathrm{mSv} / \mathrm{hr}$. With the passage of time, at 2 weeks after RAIT, majority of radioiodine was excreted and in $1 \mathrm{~g}$ of saliva the residual radioactivity was 2922 CPM, equal to $0.15 \mathrm{MBq}$ with a dose rate of 0.07 $\mathrm{mSv} / \mathrm{hr}$. The comparison of $\mathrm{CPM} \pm \mathrm{SD}$ in saliva of both benign and malignant thyroid patients after low and high RAIT is given in table 2 .

The blood samples ( $2.5 \mathrm{~mL}$ each) taken from the thyroid patients after the administration of RAIT were also examined for the presence of radioactivity under the Scintillation Radiation Detector. The mean radiation count in blood 200 sample taken from benign thyroid patients treated with low dose of radioiodine, after 3 hours of RAIT was $14781 \mathrm{CPM}$, equivalent to $0.74 \mathrm{MBq}(0.36 \mathrm{mSv} / \mathrm{hr})$ and reduced to 2642 CPM (0.13 MBq) with a dose rate 0 f $0.06 \mathrm{mSv} / \mathrm{hr}$ at 2 weeks after RAIT. On the other hand the radiation count in blood sample of neoplastic thyroid patients, at 3 hours after RAIT was 180159 CPM (9.14 MBq) with a dose rate of 4.42 $\mathrm{mSv} / \mathrm{hr}$ and at 2 weeks after RAIT it was significantly reduced to $937 \mathrm{CPM}$ equal to 0.05 MBq $(0.02 \mathrm{mSv} / \mathrm{hr})$. There was lesser stay of ${ }^{131}$ I in athyreotic patients as shown in table 3.

Table 2. Comparison of radiation count in saliva of benign and malignant patients, after radioactive iodine therapy (RAIT).

\begin{tabular}{|c|c|c|}
\hline & \multicolumn{2}{|c|}{ Radioactivity in saliva (count/min) } \\
\hline $\begin{array}{c}\text { Type of patient } \\
\text { (Dose of }{ }^{131} \text { I) }\end{array}$ & $\begin{array}{c}\text { 3 hours after RAIT } \\
\text { (Mean } \pm \text { SD) }\end{array}$ & $\begin{array}{c}\text { 2 weeks after } \\
\text { RAIT (Mean } \pm \text { SD) }\end{array}$ \\
\hline $\begin{array}{c}\text { Benign (555-1073 } \\
\text { MBq) }\end{array}$ & $339993 \pm 250289$ & $4351 \pm 4499$ \\
\hline $\begin{array}{c}\text { Malignant } \\
(3700-9250 \mathrm{MBq})\end{array}$ & $3955820 \pm 2083142$ & $2922 \pm 2728$ \\
\hline
\end{tabular}

Table 3. Comparison of radiation counts in benign and malignant thyroid patients, in blood samples $(2.5 \mathrm{~mL})$, after low and high radioactive iodine therapy (RAIT).

\begin{tabular}{|c|c|c|}
\hline & \multicolumn{2}{|c|}{ Radioactivity in blood (count/min) } \\
\hline $\begin{array}{c}\text { Type of patient } \\
\left.\text { (Dose of }{ }^{131} \mathrm{I}\right)\end{array}$ & $\begin{array}{c}\mathbf{3} \text { hours after RAIT } \\
\text { (Mean } \pm \text { SD) }\end{array}$ & $\begin{array}{c}\text { 2 weeks after } \\
\text { RAIT (Mean } \pm \text { SD) }\end{array}$ \\
\hline $\begin{array}{c}\text { Benign (555-1073 } \\
\text { MBq) }\end{array}$ & $14781 \pm 12030$ & $2642 \pm 5033$ \\
\hline $\begin{array}{c}\text { Malignant } \\
(3700-9250 \mathrm{MBq})\end{array}$ & $180159 \pm 165327$ & $937 \pm 644$ \\
\hline
\end{tabular}

Int. J. Radiat. Res., Vol. 19 No. 1, January 2021 


\section{Radiation counts in serum samples}

At 3 hours after RAIT, in benign thyroid patients the mean radioactivity in $0.6 \mathrm{~mL}$ of serum samples was $4874 \mathrm{CPM}(0.25 \mathrm{MBq})$ with a dose rate of $0.12 \mathrm{mSv} / \mathrm{hr}$, while the mean radioactivity in sera of malignant thyroid patients was $60867 \mathrm{CPM}(3.07 \mathrm{MBq}$ ) with a dose rate of $1.49 \mathrm{mSv} / \mathrm{hr}$. On the other hand at 2 weeks of RAIT the CPM in sera of benign and malignant patients exhibited inverse relationship with activity of ${ }^{131}$ I administered i.e. higher mean radioactivity $(1724 \mathrm{CPM})$ in samples of patients of low RAIT group and lesser mean radioactivity (661 CPM) in sera of patients of high RAIT group. The comparison of radiation count in sera of low and high dose RAIT patients, at 3 hours and at 2 weeks after RAIT, is presented in table 4 .

The comparison of retain-ability/binding capacity of 131I to serum or whole blood is presented in table 5. Count was significantly high in serum as compared to that in whole blood of the same amount.

Table 4. Comparison of radiation counts in serum samples $(0.6 \mathrm{~mL})$, in benign and malignant thyroid patients after radioactive iodine therapy (RAIT).

\begin{tabular}{|c|c|c|}
\hline & \multicolumn{2}{|c|}{ Radioactivity in saliva (count/min) } \\
\hline $\begin{array}{c}\text { Type of patient } \\
\text { (Dose of }{ }^{131} \text { I) }\end{array}$ & $\begin{array}{c}\text { At } 3 \text { hours after } \\
\text { RAIT (Mean } \pm \text { SD) }\end{array}$ & $\begin{array}{c}\text { At } 2 \text { weeks after } \\
\text { RAIT (Mean } \pm \text { SD) }\end{array}$ \\
\hline $\begin{array}{c}\text { Benign (555-1073 } \\
\text { MBq) }\end{array}$ & $4874 \pm 3341$ & $1724 \pm 3366$ \\
\hline $\begin{array}{c}\text { Malignant } \\
(3700-9250 \mathrm{MBq})\end{array}$ & $60867 \pm 29185$ & $661 \pm 455$ \\
\hline
\end{tabular}

Table 5. Comparison of radioactivity in the blood and serum samples of the same amount, after radioactive iodine therapy (RAIT).

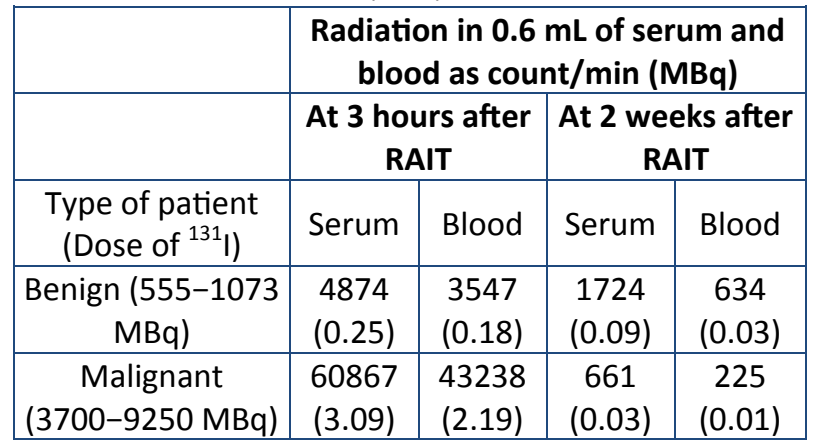

\section{Radiation count in blood slides}

The radiation count in the glass slides prepared by using $15 \mu \mathrm{L}$ of blood was also examined for the presence of radioactivity under the Scintillation Radiation Counter. In the slides prepared from blood of benign thyroid patients the radiation count at 3 hours to 2 weeks after RAIT was almost same. The radioactivity in slides prepared from the blood of malignant thyroid patients at 3 hours and 2 weeks after RAIT was 238 CPM and 193 CPM respectively. Hence the radioactivity in blood slides was comparable to that of back ground radiation (187 CPM) and thus having no significance regarding harmful effects of radiation. Radioactivity in the glass slides is given in table 6.

Table 6. Presence of radioactivity in glass slides, prepared from blood $(15 \mu \mathrm{L})$ of benign and malignant thyroid patients, after radioiodine therapy (RAIT).

\begin{tabular}{|c|c|c|}
\hline & \multicolumn{2}{|c|}{$\begin{array}{r}\text { Radioactivity in blood slides } \\
\text { (count/min) }\end{array}$} \\
\hline $\begin{array}{c}\text { Type of patient } \\
\text { (Dose of }{ }^{131} \text { I) }\end{array}$ & $\begin{array}{c}\text { At 3 hours after } \\
\text { RAIT }\end{array}$ & $\begin{array}{c}\text { At 2 weeks after } \\
\text { RAIT }\end{array}$ \\
\hline $\begin{array}{c}\text { Benign (555-1073 } \\
\text { MBq) }\end{array}$ & 201 & 200 \\
\hline $\begin{array}{c}\text { Malignant } \\
\text { (3700-9250 MBq) }\end{array}$ & 238 & 193 \\
\hline
\end{tabular}

\section{DISCUSSION}

An innovative sponge test, that was very simple, safe and quick method, was designed with the objective to collect radioactive saliva of the thyroid patients, to determine the SFR for the evaluation of salivary gland dysfunction as well as radioactivity in saliva. Reduction in SFR was due to the sialadenitis that was the common side effect of radioiodine therapy. Sialadenitis without xerostomia appears in about 39\% of patients after RAIT and is correlated with the dose of ${ }^{131}$ I administered (10).

The existence of radioactive iodine in the saliva may be explained due to residual amount of this radionuclide in oral cavity after its oral administration also by the secretion of radioiodine by the salivary glands. The protein channels, "sodium iodide symporters" are also expressed in salivary glands in addition to the 
thyrocytes. Resultantly, ${ }^{131}$ I is taken up by the tissues of salivary glands and is excreted through saliva $(11,12)$. The radioactivity in saliva of both benign and malignant thyroid patients was significantly high at 3 hours after RAIT, while at 2 weeks after RAIT, the radiation in saliva was reduced due to shorter half-life of ${ }^{131}$ I and also due to its excretion through kidneys (13). The reduction was more marked in athyreotic patients than those having the thyroid gland due to the less retention time of iodine in the body without thyroidal tissue (14). Salivary glands transport the radioactive iodine into the saliva which remains radioactive for a length of time (15). There was significant amount of radiation in the blood and serum samples at 3 hours after RAIT. The radiation count in blood and sera of these patients was dose dependent; higher in those who have taken high activity of RAIT. The clearance of ${ }^{131}$ I from the body was rapid in athyreotic patients. The drop in radioactivity in serum and blood at 2 weeks after RAIT in high RAIT group was steep and more marked due to absence of thyroid gland (thyroidectomy) (14). The retention of iodine was high in serum because the iodine was bound to the plasma proteins other than the proteins involved in the clotting of blood $(16,17)$. The magnitude of radiation in blood or body was directly proportional to the activity of ${ }^{131}$ I administered and also the fractions of radioactive iodine attached to the plasma proteins and other molecules in the tissues $(18,19)$.

\section{CONCLUSION}

The innovative sponge test is the simple, quick and safe method for the collection of radioactive saliva from the thyroid patients after RAIT. The salivary flow rate in thyroid patients seems to be affected by ${ }^{131}$ I therapy and has decreasing trend even upto 2 weeks after RAIT. The amount of radioactivity in saliva, blood and serum samples determined by the NaI (TI) Scintillation Radiation Detector was very high at 3 hours after RAIT and reduced to the minimal levels at 2 weeks after RAIT. The presence of radioactivity in the samples, especially the 202 saliva, upto 2 weeks was considerable and the patients are advised not to have any contact with young ones and with the pregnant women for at least 2 weeks. Safety measures should also be taken by the laboratory personals while handling radioactive saliva, blood and serum samples. Furthermore such samples must be labelled as radioactive ones while transporting them across the borders.

\section{Conflicts of interest: Declared none.}

\section{REFERENCES}

1. Jahan S, Rouf A, Aziz S, Ateeq M (2018) Thyroid disorders: spectrum of thyroid disorders an experience in Gujranwala region of Punjab. Prof Med J, 25(5).

2. Verburg FA (2019) Radioiodine Therapy of Thyroid Cancer. In: Nuclear Medicine Therapy, 35-42. Springer, Cham.

3. Russell SJ, Peng KW, Lech P, inventors; Mayo Foundation for Medical Education, assignee (2016) Radiotracer imaging using sodium iodide symporter polypeptides. United States patent application US 14/777, 348.

4. Lee SM, Lee JW, Kim SY, Han SW, Bae WK (2013) Prediction of risk for symptomatic sialadenitis by posttherapeutic dual 131 I scintigraphy in patients with differentiated thyroid cancer. Ann. Nucl. Med, 27(8): 700-709.

5. Misdaq MA, Harrass H, Karime M, Matrane A (2016) Determination of Beta Radiation Dose to the Thyroid Gland from the Ingestion of 131 I by Patients. Am J Environ Prot, 5(6): 168-178.

6. Wolff A, Begleiter A, Moskona D (1997) A novel system of human submandibular/sublingual saliva collection. J Dent Res, 76(11): 1782-1786.

7. Prekeges J (2012) In: Nuclear Medicine Instrumentation. Jones \& Bartlett Publishers.

8. Evron S, Tress V, Ezri T, Szmuk P, Landau O, Hendel D (2007) The importance of blood sampling site for determination of hemoglobin and biochemistry values in major abdominal and orthopedic surgery. J Clin Anesth, 19(2): 92 $-96$.

9. Sreebny L M and Vissink A (Eds.) (2010) Dry mouth, the malevolent symptom: a clinical guide. John Wiley \& Sons. (pp 43-44)

10. Grewal RK, Larson SM, Pentlow KS (2009) Salivary gland side effects commonly develop several weeks after initial radioactive iodine ablation. Journal of Nuclear Medicine, 50 (10): 1605-1610.

11. Van Nostrand D (2011) Sialoadenitis secondary to 131। therapy for well-differentiated thyroid cancer. Oral Dis, 17 (2): 154-161.

12. La Perle KM, Kim DC, Hall NC, Bobbey A, Shen DH, Nagy RS (2013) Modulation of sodium/iodide symporter expression

Int. J. Radiat. Res., Vol. 19 No. 1, January 2021 
in the salivary gland. Thyroid, 23(8): 1029-1036.

13. Remy H, Borget I, Leboulleux S, Guilabert N, Lavielle F, Garsi J, kkk (2008) 131l effective half-life and dosimetry in thyroid cancer patients. J Nucl Med, 49(9): 1445-1450.

14. Kramer HG, M. Hauck B, J. Chamberlain M (2002) Biological half-life of iodine in adults with intact thyroid function and in athyreotic persons. Radiat Prot Dosim, 102(2): 129135.

15. Jentzen W, Balschuweit D, Schmitz J, Freudenberg L, Eising E, Hilbel T et al. (2010) The influence of saliva flow stimulation on the absorbed radiation dose to the salivary glands during radioiodine therapy of thyroid cancer using 124 I PET (/CT) imaging. Eur J Nucl Med Moll, 37(12):22982306.

16. Freedberg AS, Ureles A, Hertz S (1949) Serum level of protein bound radioactive iodine (I131) in the diagnosis of hyperthyroidism. Proceedings of the SEBM, 70(4): 679-
682.

17. Barker S (2016) M serum protein-bound iodine (PI) as an objective method of evaluating thyroid function. Such a procedure is based on the well-established concept that the iodine-containing substance thyroxine either is the thyroid hormone or is a part of it. In as much as the thyroid is intimately concerned. I Clin Endocrinol Metab, 20: 61.

18. Blomfield, G W, Eckert H, Fisher M (1959) Treatment of hyperthyroidism with ${ }^{131} \mathrm{l}$, a review of 500 cases. Brit Med J, 1: 63-79.

19. Foss CA, Plyku D, Ordonez AA, Sanchez-Bautista J, Rosenthal HB, Minn I, et al. (2018) Bio-distribution and Radiation Dosimetry of 124I-DPA-713, a PET Radiotracer for Macrophage-Associated Inflammation. J Nuc Med, 59(11): 17511756. 
